\title{
Two Cases of Elderly-Onset Hereditary Neuropathy with Liability to Pressure Palsy Manifesting Bilateral Peroneal Nerve Palsies
}

\author{
Norihiko Kawaguchi Naoki Suzuki Maki Tateyama \\ Yoshiki Takai Tatsuro Misu Ichiro Nakashima \\ Yasuto Itoyama Masashi Aoki \\ Department of Neurology, School of Medicine, Tohoku University, Sendai, Japan
}

\section{Key Words}

Hereditary neuropathy with liability to pressure palsy · Elderly-onset .

Bilateral peroneal nerve palsies · Peripheral myelin protein 22 . 'Seiza'

\begin{abstract}
Hereditary neuropathy with liability to pressure palsy (HNPP) is characterized by recurrent focal neuropathies, which usually become symptomatic in the second or third decade of life. However, clinical phenotypic heterogeneity among patients with HNPP has recently been reported. Certain patients show polyneuropathy-type diffuse nerve injuries, whereas others remain asymptomatic at older ages. We present two cases of elderly-onset bilateral peroneal nerve palsies with diffuse muscle weakness in the lower limbs and glove-andstocking type sensory disturbance. Both patients were diagnosed with HNPP by genetic analyses that detected deletions of chromosome $17 \mathrm{p} 11.2$ in peripheral myelin protein 22 genes. Their clinical courses suggested that the Japanese sitting style termed 'seiza', a way of sitting on the floor with the lower legs crossed under the thighs, was a precipitating factor for the bilateral peroneal nerve palsies.
\end{abstract}

\section{Introduction}

Hereditary neuropathy with liability to pressure palsy (HNPP) is an autosomal dominant disorder characterized by recurrent focal neuropathies that commonly occur at entrapment sites such as the carpal tunnel at the wrist and the head of the fibula at the knee $[1,2]$. Tomacula formation, a sausage-like focal thickening of myelin in the 
peripheral nerve, is a histological hallmark of HNPP [3]. Typical HNPP patients can be diagnosed clinically, and the diagnoses are confirmed by detecting deletions of chromosome 17p11.2 in peripheral myelin protein 22 (PMP22) genes. Recent studies have demonstrated a phenotypic heterogeneity among patients with deletions of the PMP22 genes [2, 4]. Certain patients showed recurrent entrapment neuropathies, whereas others presented Charcot-Marie-Tooth disease-like polyneuropathy. The onset age is variable, and certain carriers could be asymptomatic in adulthood. In addition to the deletions of the PMP22 genes, other mutations of PMP22 genes have been shown to cause HNPP phenotypes [5-7]. Clinical courses are modified by not only the types of the genetic mutations but also environmental factors such as focal compressions and traumas. Thus, careful neurological assessments, including observation of patients' ways of life, histological examinations and genetic analyses, are necessary to diagnose HNPP. We present the cases of two patients with elderly-onset HNPP who developed bilateral peroneal nerve palsies. Their clinical histories suggested that the Japanese sitting style 'seiza' was a possible aggravating factor for the peroneal nerve palsy.

\section{Case Presentation}

\section{Case 1}

An 83-year-old woman developed left drop foot, followed after several days by right drop foot. She was admitted to our hospital by stretcher because she could not stand up by herself. There was no family history of neurological diseases. She had experienced transient bilateral drop foot when she was 78 years old, and the palsy was resolved without medical care after 2 months. Neurological examination revealed bilateral peroneal nerve palsies, muscle weakness in the lower limbs, gloveand-stocking type sensory disturbance and areflexia in the four limbs. Routine hematological examination showed normal results except for an antinuclear antibody titer elevation (1:160). Cerebrospinal fluid examination was normal. In the nerve conduction study (table 1), compound motor action potentials (CMAPs) were not evoked in bilateral peroneal nerves at either the knees or the heels. The motor nerve conduction velocities were decreased in the median, ulnar, and tibial nerves, and temporal dispersions were observed in the ulnar nerves. The amplitudes of CMAPs were decreased in the ulnar and tibial nerves [8]. Sensory nerve action potentials were not evoked in the sural nerves. Cervical magnetic resonance imaging showed a mild hypertrophy of the spinal roots with gadolinium enhancement. Histological examination of the sural nerve biopsy revealed that the myelinated fiber density was reduced $\left(5,570 / \mathrm{mm}^{2}\right)$ ( fig. 1a). Numerous thinly myelinated fibers were observed. There was no histological evidence of angiitis. In the teased preparation, $94 \%$ of the nerve fibers showed segmental demyelination and remyelination, and $75 \%$ of the abnormal fibers contained tomacula formations (fig. 1b). Genetic analysis demonstrated deletions of 17p11.2 in PMP22 genes, confirming the diagnosis of HNPP (fig. 1c).

The patient habitually sat in the 'seiza' style on the bed before admission. We advised her to avoid this sitting style after HNPP was diagnosed. After a few weeks, her muscle weakness around the ankle gradually improved. Finally, she was able to walk using assistive devices when she was discharged.

Case 2

A 76-year-old woman with a history of lumbar herniation noticed left leg weakness and was admitted to our hospital. She had received right ankle arthrodesis for a sudden right drop foot when she was 69 years old. Her family history was significant in that her 77-year-old brother had suffered left drop foot for 30 years. Neurological examination revealed bilateral peroneal nerve palsies. In addition, distal-dominant muscle weakness in the lower limbs, glove-and-stocking type sensory disturbance and areflexia in the four limbs were observed. Routine hematological and cerebrospinal fluid examination showed no abnormalities. In the nerve conduction study (table 1), CMAPs were not evoked in the bilateral peroneal nerves at either the knees or the ankles. In the bilateral tibial nerves, the nerve conduction velocities were decreased, and temporal dispersions were observed. Sensory nerve action potentials were not evoked in the sural nerves. Sural nerve biopsy revealed a reduced myelinated fiber density $\left(5,430 / \mathrm{mm}^{2}\right)$. Numerous thinly myelinated fibers were observed. There was 
no histological evidence of angiitis. In the teased preparation, $38 \%$ of the nerve fibers showed segmental demyelination and remyelination, and $10 \%$ of the abnormal fibers contained tomacula formations. Genetic analysis demonstrated deletions of 17p11.2 in PMP22 genes, confirming the diagnosis of HNPP. The patient began to sit in the 'seiza' style before admission to our hospital, and the 'seiza' style was considered to have affected the development of bilateral peroneal nerve palsies.

\section{Discussion}

Our two patients with HNPP presented atypical characteristics. First, their ages at the first episodes (drop foot) were remarkably advanced (case 1: 78 years, case 2: 69 years); most HNPP patients are diagnosed during their second or third decades [1, 9, 10]. Second, the clinical and electrophysiological findings of the two cases showed polyneuropathy-type sensorimotor abnormalities. A common electrophysiological finding in HNPP is a multifocal slowing of nerve conduction at the entrapment sites with a diffuse increase in distal motor latencies $[1,2]$. However, both cases showed diffuse demyelination and axonal damage in the lower legs without a focal slowing of the nerve conduction velocity at the entrapment site. Therefore, without genetic and histological analyses, it was difficult to rule out other polyneuropathy syndromes such as chronic inflammatory demyelinating polyradiculoneuropathy and Charcot-MarieTooth disease.

The most prominent feature of our patients was bilateral peroneal nerve palsy. The peroneal nerve is vulnerable to compressions or minor traumas, and unilateral peroneal nerve palsy has been reported in Western countries where people prefer to sit on chairs with their legs crossed [11]. In contrast, bilateral peroneal nerve palsies have been exceptionally reported in operative complications [12] and bedridden hospitalizations [13]. Our observation suggested that the sitting style 'seiza' was a possible trigger of the bilateral peroneal nerve palsies in the two patients who already had severe neuronal damage in the peroneal nerves. The reason for this suggestion was that they developed bilateral drop foot after they moved to nursing homes and began to sit in the 'seiza' style frequently. Moreover, their bilateral peroneal nerve palsies were ameliorated after they began to avoid the 'seiza' style.

'Seiza' is a traditional Japanese style of sitting on the floor and is performed in daily life and in lessons in calligraphy and flower arrangement among the elderly. Similar sitting styles are also observed during religious services in Asian countries. To sit in the 'seiza' style, one folds the legs under the thighs and rests the buttocks on the heels. As a result, the bilateral peroneal nerves are stretched and compressed under the thighs. This effect leads to the significant decrements in CMAPs of peroneal nerves in the Japanese elderly [9]. Additionally, age-related loss of subcutaneous fat tissue could make the peripheral nerves more vulnerable to compressions at the entrapment sites $[14,15]$. These effects explain why our two patients became symptomatic later in life.

In conclusion, HNPP could remain asymptomatic until old age and develop with atypical symptoms such as bilateral peroneal nerve palsies. Correct diagnosis and the avoidance of precipitating factors could prevent further progress in compression neuropathies in HNPP. 


\section{Acknowledgement}

We thank Masumi Toyosawa for excellent technical assistance. We also thank Mr. Brent Bell for reading the manuscript. Dr. Misu has been funded as the primary investigator by the Grants-in-Aid for Scientific Research from the Ministry of Education, Science, and Technology of Japan. Dr. Nakashima has received research funding from Mitsubishi Chemical Medience Corporation, and the Grants-in-Aid for Scientific Research from the Ministry of Education, Science and Technology. Dr. Itoyama has been funded as the primary investigator by the Grants-in-Aid for Scientific Research from the Ministry of Education, Science, and Technology of Japan and the Ministry of Health, Labor and Welfare of Japan. Dr. Aoki has been funded as the primary investigator by the Grants-in-Aid for Scientific Research from the Ministry of Education, Science, and Technology of Japan, and the Ministry of Health, Labor and Welfare of Japan.

\section{Disclosure Statement}

Dr. Misu received honoraria for speaking from Bayer Schering Pharma and Astellas Pharma. Dr. Nakashima has received funding for travel and received speaker honoraria from Bayer Schering Pharma, and Biogen Idec. Dr. Itoyama has received honoraria for speaking or consulting from Bayer Schering Pharma, Biogen Idec Japan, Chemo-Sero-Therapeutic Research Institute and Tanabe Mitsubishi Pharma. 
Table 1. Summary of the nerve conduction study

\begin{tabular}{|c|c|c|c|c|c|c|}
\hline & \multicolumn{2}{|c|}{ Case 1} & \multicolumn{2}{|c|}{ Case 2} & \multirow{2}{*}{$\begin{array}{l}\text { Controla } \\
\text { (adult) }\end{array}$} & \multirow{2}{*}{$\begin{array}{l}\text { Controla } \\
\text { (51-81 years) }\end{array}$} \\
\hline & right & left & right & left & & \\
\hline \multicolumn{7}{|l|}{ Motor NCS } \\
\hline \multicolumn{7}{|l|}{ Median nerve (APB) } \\
\hline $\mathrm{MNCV}, \mathrm{m} / \mathrm{s}$ & 42.7 & 45.7 & 49.0 & 50.6 & $55.6 \pm 2.9$ & $54.5 \pm 4.0$ \\
\hline Distal latency, ms & 6.1 & 5.3 & 5.6 & 6.2 & $3.49 \pm 0.34$ & n.a. \\
\hline CMAP, $\mathrm{mV}$ & 7.2 & 12.1 & 3.7 & 6.4 & $7.0 \pm 3.0$ & n.a. \\
\hline F-wave latency, ms & 24.7 & 21.7 & 21.2 & 24.7 & $26.6 \pm 2.2$ & n.a. \\
\hline \multicolumn{7}{|l|}{ Ulnar nerve (ADM) } \\
\hline $\mathrm{MNCV}, \mathrm{m} / \mathrm{s}$ & 53.1 & 43.7 & 50.2 & 56.3 & $57.8 \pm 2.1$ & $53.3 \pm 3.2$ \\
\hline Distal latency, ms & 4.0 & 4.7 & 4.2 & 3.5 & $6.10 \pm 0.69$ & n.a. \\
\hline CMAP, mV & 3.7 & 3.4 & 5.4 & 6.8 & $5.5 \pm 2.0$ & n.a. \\
\hline F-wave latency, ms & 28.3 & 32.2 & 29.8 & 27.3 & $27.6 \pm 2.2$ & n.a. \\
\hline \multicolumn{7}{|l|}{ Tibial nerve (AHM) } \\
\hline $\mathrm{MNCV}, \mathrm{m} / \mathrm{s}$ & n.e. & 43.2 & 35.0 & 37.8 & $43.6 \pm 5.1$ & $43.9 \pm 4.3$ \\
\hline Distal latency, ms & n.e. & 5.4 & 6.1 & 4.7 & $3.96 \pm 1.00$ & n.a. \\
\hline CMAP, mV & n.e. & 1.3 & 5.4 & 2.3 & $5.8 \pm 1.9$ & n.a. \\
\hline F-wave latency, ms & n.e. & 57.4 & 55.5 & 47.3 & $47.7 \pm 5.0$ & n.a. \\
\hline \multicolumn{7}{|l|}{ Peroneal nerve(EDB) } \\
\hline CMAP, mV & n.e. & n.e. & n.e. & n.e. & $5.1 \pm 2.3$ & n.a. \\
\hline \multicolumn{7}{|l|}{ Senrosy NCS } \\
\hline \multicolumn{7}{|l|}{ Median nerve (digit 2) } \\
\hline $\mathrm{SCV}, \mathrm{m} / \mathrm{s}$ & n.e. & 35.3 & 77.0 & 51.0 & $65.8 \pm 3.8$ & $62.8 \pm 5.4$ \\
\hline Distal latency, ms & n.e. & 3.5 & 5.2 & 4.0 & $2.84 \pm 0.34$ & n.a. \\
\hline SNAP, $\mu \mathrm{V}$ & n.e. & 21.7 & 8.0 & 10.0 & $38.4 \pm 15.6$ & n.a. \\
\hline \multicolumn{7}{|l|}{ Ulnar nerve (digit 5) } \\
\hline $\mathrm{SCV}, \mathrm{m} / \mathrm{s}$ & 31.8 & 28.9 & n.d. & n.d. & $67.1 \pm 4.7$ & $56.7 \pm 3.7$ \\
\hline Distal latency, ms & 4.4 & 4.0 & n.d. & n.d. & $5.67 \pm 0.59$ & n.a. \\
\hline SNAP, $\mu \mathrm{V}$ & 32.3 & 10.2 & n.d. & n.d. & $35.4 \pm 14.7$ & n.a. \\
\hline \multicolumn{7}{|l|}{ Sural nerve } \\
\hline SNAP, $\mu \mathrm{V}$ & n.e. & n.e. & n.e. & n.e. & $18.9 \pm 6.7$ & n.a. \\
\hline
\end{tabular}

NCS = Nerve conduction study; $\mathrm{APB}=$ abductor pollicis brevis; MNCV = motor nerve conduction velocity; $\mathrm{ADM}=$ abductor digiti minimi; $\mathrm{AHM}=$ abductor hallucis muscle; $\mathrm{EDB}=$ extensor digitorum brevis; $\mathrm{SCV}=$ sensory nerve conduction velocity; n.e. = not evoked; n.d. = not done; n.a. = not available. Upper/lower limt of normal was calculated as mean $+1 /-1$ standard deviation, respectively. a From reference [8]. 


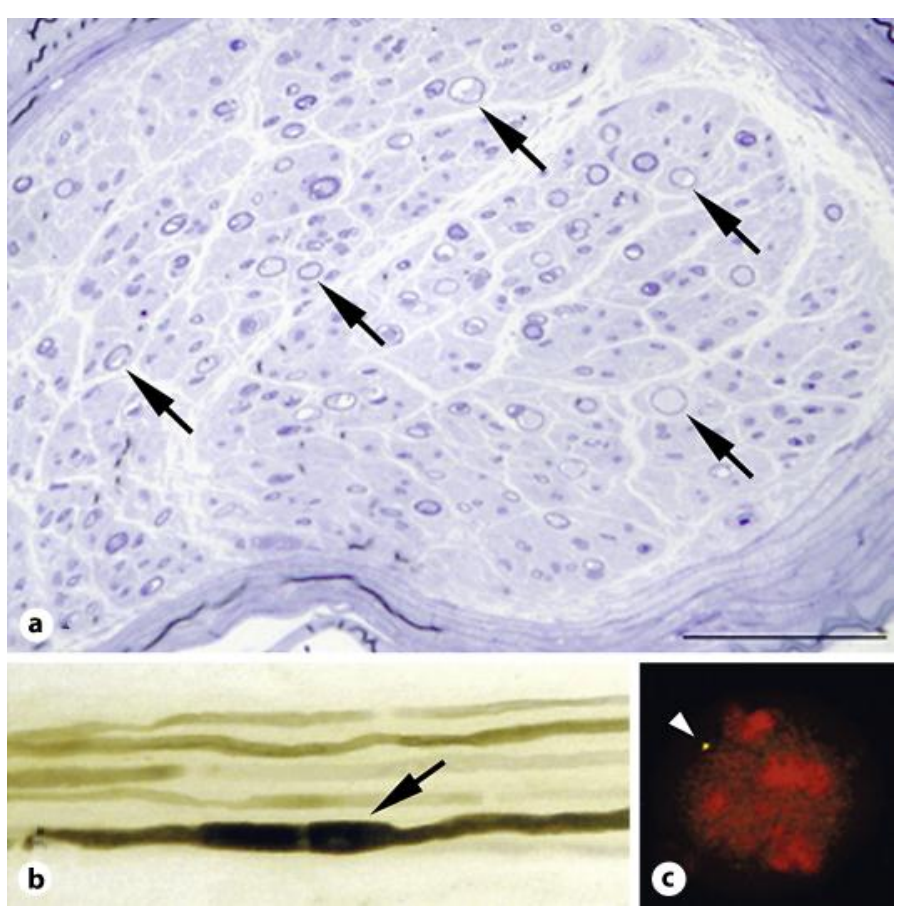

Fig. 1. Histological and genetic results in case 1. a A cross section of the left sural nerve with toluidine blue staining showed a decrease in the myelinated fiber density. Thinly myelinated fibers were observed (arrows). Scale bar $=100 \mu \mathrm{m}$. $\mathbf{b}$ Teased fiber preparation demonstrated the characteristic tomacula formation (arrow). Other thinly myelinated fibers were observed. c Genetic analysis with the FISH method showed only one PMP22 probe signal in 97\% of the white blood cells. The deletion of one copy of the PMP22 genes, compared with the presence of two copies in a normal control, supported the diagnosis of HNPP. One existing copy of the PMP22 gene is indicated (arrow head).

\section{References}

1 Gouider R, LeGuern E, Gugenheim M, Tardieu S, Maisonobe T, Leger JM, Vallat JM, Agid Y, Bouche P, Brice A: Clinical, electrophysiologic, and molecular correlations in 13 families with hereditary neuropathy with liability to pressure palsies and a chromosome 17p11.2 deletion. Neurology 1995;45:2018-2023.

2 Mouton P, Tardieu S, Gouider R, Birouk N, Maisonobe T, Dubourg O, Brice A, LeGuern E, Bouche P: Spectrum of clinical and electrophysiologic features in HNPP patients with the $17 \mathrm{p} 11.2$ deletion. Neurology 1999;52:1440-1446.

-3 Sander S, Ouvrier RA, McLeod JG, Nicholson GA, Pollard JD: Clinical syndromes associated with tomacula or myelin swellings in sural nerve biopsies. J Neurol Neurosurg Psychiatry 2000;68:483-488.

4 Pareyson D, Scaioli V, Taroni F, Botti S, Lorenzetti D, Solari A, Ciano C, Sghirlanzoni A: Phenotypic heterogeneity in hereditary neuropathy with liability to pressure palsies associated with chromosome 17p11.2-12 deletion. Neurology 1996;46:1133-1137.

-5 Lenssen PP, Gabreels-Festen AA, Valentijn LJ, Jongen PJ, van Beersum SE, van Engelen BG, van Wensen PJ, Bolhuis PA, Gabreels FJ, Mariman EC: Hereditary neuropathy with liability to pressure palsies. Phenotypic differences between patients with the common deletion and a PMP22 frame shift mutation. Brain 1998;121:1451-1458.

6 Saporta MA, Katona I, Zhang X, Roper HP, McClelland L, Macdonald F, Brueton L, Blake J, Suter U, Reilly MM, Shy ME, Li J: Neuropathy in a human without the PMP22 gene. Arch Neurol 2011;68:814-821.

7 Nodera H, Nishimura M, Logigian EL, Herrmann DN, Kaji R: HNPP due to a novel missense mutation of the PMP22 gene. Neurology 2003;60:1863-1864.

8 Kimura J: Electrodiagnosis in disease of nerve and muscle: principles and practice, ed 3. New York, Oxford University Press, 2001, pp 130-177. 
-9 Koike H, Hirayama M, Yamamoto M, Ito H, Hattori N, Umehara F, Arimura K, Ikeda S, An do Y, Nakazato M, Kaji R, Hayasaka K, Nakagawa M, Sakoda S, Matsumura K, Onodera O, Baba M, Yasuda H, Saito T, Kira J, Nakashima K, Oka N, Sobue G: Age associated axonal features in HNPP with 17p11.2 deletion in Japan. J Neurol Neurosurg Psychiatry 2005;76:1109-1114.

10 Pareyson D, Botti S, Sghirlanzoni A, Taroni F: PMP22 frameshift mutation and hereditary neuropathy with liability to pressure palsies. Neurology 1997;49:1478-1479.

11 Weiss II: Crossed leg palsy; with report of a recurrent case. Calif Med 1949;71:33-35.

12 Fukuda H: Bilateral peroneal nerve palsy caused by intermittent pn eumatic compression. Intern Med 2006;45:93-94.

13 Tacconi P, Manca D, Tamburini G, Cannas A, Giagheddu M: Bed footboard peroneal and tibial neuropathy. A further unusual type of Saturday night palsy. J Peripher Nerv Syst 2004;9:54-56.

14 Cruz-Martinez A, Arpa J, Palau F: Peroneal neuropathy after weight loss. J Peripher Nerv Syst 2000;5:101-105.

15 Landau ME, Barner KC, Campbell WW: Effect of body mass index on ulnar nerve conduction velocity, ulnar neuropathy at the elbow, and carpal tunnel syndrome. Muscle Nerve 2005;32:360-363. 